\title{
Pyogenic bacterial lower respiratory tract infection in human immunodeficiency virus-infected patients
}

\author{
C. Mayaud, A. Parrot, J. Cadranel
}

Pyogenic bacterial lower respiratory tract infection in human immunodeficiency virusinfected patients. C. Mayaud, A. Parrot, J. Cadranel. (C)ERS Journals Ltd 2002.

ABSTRACT: In human immunodeficiency virus (HIV)-infected patients, bacterial lower respiratory tract infections are the most frequent respiratory diseases. They are frequently the first clinical manifestation of HIV infection.

The incidence and severity of bacterial lower respiratory tract infections increase with the degree of immunosuppression. At the acquired immune deficiency syndrome (AIDS) stage, the responsible bacteria and clinical presentation may be atypical. Bacterial pneumonia may be fatal, particularly in AIDS patients, and its occurrence is predictive of a reduced survival time.

Pneumococcal vaccine is recommended in patients with a CD4 T-lymphocyte count of $>200$ cells $\cdot \mathbf{m m}^{-3}$ and cotrimoxazole (trimethoprim/sulfamethoxazole) in patients with a CD4 T-lymphocyte count of $<\mathbf{2 0 0}$ cells $\cdot \mathbf{m m}^{-3}$. Unfortunately, such prophylaxis remains insufficiently prescribed and its protective effect is limited.

Highly active antiretroviral treatment has dramatically reduced the incidence of lower respiratory tract infection due to Pseudomonas aeruginosa and opportunistic bacteria. In contrast, successful highly active antiretroviral therapy slightly decreased the risk of bacterial pneumonia due to usual bacteria, even in patients on successful highly active antiretroviral therapy.

Eur Respir J 2002; 20: Suppl. 36, 28s-39s.
Respiratory Division, Tenon Hospital, Paris, France.

Correspondence: C. Mayaud, Service de Pneumologie et de Réanimation respiratoire, Hôpital Tenon, AP-HP, 4 rue de la Chine, 75020 Paris, France.

Fax: 33156017002

E-mail: charles.mayaud@

tnn.ap-hop-paris.fr

Keywords: Acquired immune deficiency syndrome

bacterial bronchitis

bacterial pneumonia

human immunodeficiency virus infection prophylaxis

Received: February 52002

Accepted after revision: March 182002
At the beginning of the acquired immune deficiency syndrome (AIDS) epidemic, it was clear that the lung of human immunodeficiency virus (HIV)-infected patients was the major target for many infections and tumours, and, in the first series reported, Pneumocystis carinii pneumonia (PCP) and bronchopulmonary localisation of Kaposi's sarcoma were mainly incriminated $[1,2]$. It is only gradually that pyogenic bacteria have been recognised to be a major cause of lower respiratory tract infection (LRTI) in HIVinfected patients, whatever their level of immunosuppression [3-5].

During the first decade of the AIDS epidemic, it was shown that the occurrence of pyogenic bacterial infection might partly be prevented by the use of prophylaxis, and, more recently, the use of highly active antiretroviral therapy (HAART) has been shown to have an indirect (immune restoration) but long-lasting preventive effect. Thus, in the current world, three very different situations have to be considered [6].

\section{Bacterial lower respiratory tract infections in human immunodeficiency virus-infected patients who do not receive prophylaxis or antiretroviral treatment}

This situation concerns the majority of HIVinfected patients in developing countries, but, in developed countries, some patients without knowledge of their seropositivity or without appropriate follow-up are also concerned. In such patients, the natural history of HIV-associated LRTI is obviously the same as it was at the beginning of the AIDS epidemic.

Incidence of pyogenic bacterial lower respiratory tract infection

Incidence in developed countries. In developed countries, WaLlace et al. [7] examined trends in the incidence of specific respiratory disorders in a multicentric cohort with progressive HIV disease during a 5-yr period. Individuals with a wide range of HIV disease severity and belonging to the three main transmission categories were evaluated at regular intervals and for episodic respiratory symptoms using standard diagnostic algorithms. Acute bronchitis and bacterial pneumonia were the most common respiratory diseases of cohort members. The respective incidences per 100 person-yrs were 13.7 for bronchitis and 5.5 for bacterial pneumonia. When HIV-infected individuals were compared with controls of similar age, race, sex and transmission group, the incidence rates were two-fold greater for bronchitis and six-fold greater for bacterial pneumonia [7].

Similar results were found in a US case controlled study performed in an intravenous drug user cohort, in which the incidence of bacterial pneumonia per 100 
person-years was 1.93 in HIV-seropositive and 0.45 in HIV-seronegative subjects [8].

Finally, in an Italian intravenous drug user cohort, Boschini et al. [9] reported 149 episodes of community-acquired pneumonia among HIV-seropositive patients and 61 among $\mathrm{HIV}$-seronegative subjects with incidence rates per 1,000 person-yrs of 90.5 and 14.2 , respectively.

Incidence in developing countries. GILKs et al. [10] followed up a cohort of HIV-positive and -negative female sex workers in Nairobi, Kenya. The incidence rates of pneumonia per 1,000 person-yrs were 38.6 in HIV-seropositive females and 3.7 in HIV-seronegative females. More precisely, the incidence rates of invasive pneumococcal disease and pneumococcal bacteraemia per 1,000 person-yrs were 42.5 and 23.8 in HIVseropositive females and 3.7 and 0 in HIV-seronegative females, respectively. The relative risk of development of invasive pneumococcal disease with underlying HIV infection was 17.8 (95\% confidence interval 2.5-126.5) [10]. These high incidence rates explain why, in prospective studies, pyogenic bacteria as well as $\mathrm{Myco}$ bacterium tuberculosis were recognised as the major cause of respiratory diseases in HIV-infected Africans [11-13].

Risk factors for bacterial lower respiratory tract infection. The risk of bacterial pneumonia is not the same in all HIV-infected persons. The most important risk factor for bacterial pneumonia is the degree of immunosuppression, as reflected by the CD4 T-lymphocyte count. In the previously mentioned US cohort study [7, 14], acute bronchitis was equally prevalent during all stages of HIV disease, whereas the risk of bacterial pneumonia was clearly related to the study entry CD4 count $(2.3,6.8$ and 10.8 episodes per 100 person-yrs in the subgroups of cohort members with $>500,200-500$ and $<200$ CD4 T-lymphocytes $\cdot \mathrm{mm}^{-3}$ ) $[14,15]$. A similar relationship between a decreased CD4 T-lymphocyte count and an increased risk of bacterial pneumonia has been found in European studies $[9,16]$. Other risks factors for bacterial pneumonia have also been identified. HirschTick et al. [15] showed that the risk was greater in intravenous drug users than in homosexual male or female partners. In the same study, tobacco was equally shown to be an independent risk factor in the subgroup of HIVseropositive subjects with $<200$ CD4 lymphocytes. $\mathrm{mm}^{-3}$. Another risk factor is neutropenia, which may result from direct retroviral infection, the use of antiretroviral and other drug therapy, systemic opportunistic infections and autoimmune mechanisms [17]. Splenectomy $[18,19]$, previous pneumonia, whatever the cause [8], smoking illicit drugs [8] and low Karnofsky score [14] have also been associated with bacterial pneumonia.

Regarding specifically nosocomial pneumonia, advanced HIV infection, high Acute Physiology and Chronic Health Evaluation III score and central nervous system diseases have been shown to be risk factors in the case controlled study of TUMBARELLO et al. [20].
Bacteria responsible for lower respiratory tract infection

The first series investigating bacterial pneumonia in patients with AIDS or AIDS-related complex have shown the predominant role of Streptococcus pneumoniae and, to a lesser degree, Haemophilus influen$z a e$, in adults as well as children [21], in developed countries [22-25] and developing countries [10, 13]. Subsequently, other series with greater numbers of patients followed up over a long period have emphasised that three kinds of bacteria might be the cause in HIV-infected patients.

Typical pyogenic bacteria. In all series, typical pyogenic bacteria and, more particularly, $S$. pneumoniae and $H$. influenzae, were the major responsible bacteria. For example, in a French clinical epidemiology database, $S$. pneumoniae and $H$. influenzae were the cause of 52 and $16 \%$ of bacteriologically confirmed pneumonia, respectively [26]. Similarly, in the US cohort study of Hirschtick et al. [15], S. pneumoniae and $H$. influenzae were found in 52 and $15 \%$ of patients with confirmed pneumonia, respectively.

In the African cohort study by GiLks et al. [10], $91 \%$ of pneumococcal serotypes incriminated in HIVseropositive adults were included in the currently available pneumococcal vaccine. The principal serotypes were 1, 3, 5, 7, 19 and 23. In South Africa, 83\% of serotypes incriminated in HIV-seropositive children were included in the nine-valent conjuguated pneumococcal vaccine [27]. Finally, in the USA, FrANKEL et al. [28] also found that $90 \%$ of the serotypes responsible for invasive pneumococcal disease, particularly serotypes $9,14,6 \mathrm{~b}$ and $22 \mathrm{f}$, were equally included in the polyvalent pneumococcal vaccine.

Concerning susceptibility of $S$. pneumoniae to penicillin, BEDos et al. [29] performed a retrospective study in France, to investigate the susceptibility of $10,350 \mathrm{~S}$. pneumoniae strains to penicillin $\mathrm{G}$ and identify risk factors for infection with nonsusceptible strains. In a logistic regression model, HIV infection was associated with nonsusceptible strains (odds ratio (OR) 2.01). In US children, MAO et al. [30] also found that HIV-infected children were more likely to yield isolates exhibiting penicillin resistance, but such a relation was not found by FrANKEL et al. [28] in US adults. In South Africa, Jones et al. [27] also found that resistance to penicillin was increased in $S$. pneumoniae isolates from HIV-infected patients.

Bacterial pneumonia due to $H$. influenzae $[25,31]$ occurred less frequently than that due to $S$. pneumoniae and was particularly observed in patients with $<100$ CD4 T-lymphocytes $\cdot \mathrm{mm}^{-3}$ [32].

If bacteria other than those usually responsible for community-acquired pneumonia in HIV-negative adults are considered, Legionella pneumophila serogroup 1 has been infrequently incriminated in HIV-infected subjects [9]. In a cohort of HIV-infected patients from the US air force, BLATT et al. [33] identified eight cases of legionella pneumonia. These cases represented $1.7 \%$ of patients with late-stage HIV infection and five of these cases were nosocomial. At the present time, 
L. pneumophila remains an uncommon pathogen in HIV-infected people.

Besides encapsulated pathogens and L. pneumophila, Boschini et al. [9] found a high incidence of community-acquired pneumonia due to Chlamydia pneumoniae (incidences per 1,000 patient-yrs of 18.64 for $S$. pneumoniae, 12.43 for $H$. influenzae and 11.30 for $C$. pneumoniae). This diagnosis was based on serological criteria, and, during the period of the study, there were two outbreaks of $C$. pneumoniae infection. In Germany, DALHOFF et al. [34] detected $C$. pneumoniae by polymerase chain reaction in bronchoalveolar lavage (BAL) fluid from 13\% of hospitalised HIV-infected patients. However, acute respiratory symptoms were not always present, and, in 50\% of cases, copathogens were found in the BAL fluid. Today, the precise role of $C$. pneumoniae as a cause of community-acquired pneumonia in HIV-infected patients remains debatable.

Atypical pyogenic bacteria. Atypical pyogenic bacteria may also be the causative agent, particularly in patients with advanced HIV disease. For example, Klebsiella pneumoniae, other members of the Enterobacteriaceae family and Pseudomonas aeruginosa were present in 13, 10 and $8 \%$ of cases, respectively, of confirmed pneumonia in the US cohort study of Hirschtick et al. [15]. Similarly, $P$. aeruginosa, the Enterobacteriaceae family and Staphylococcus aureus were the cause of 25, 9 and $10 \%$ of community-acquired pneumonia, respectively, in the series of AFEssA et al. [31]. These kinds of pathogen and their relative frequencies were consistent with most published reports [16, 35-37] and the microbiological data in the French epidemiological database [26].

Concerning $S$. aureus, LEVINE et al. [35] recovered this pathogen in $23 \%$ of respiratory tract cultures performed in 129 consecutive HIV-infected patients with an episode of respiratory disease. According to the authors, this presence of $S$. aureus was found to be community-acquired pneumonia in $28 \%$ of cases, of indeterminate significance in $62 \%$ and colonisation in $10 \%$. None of the patients with pneumonia were neutropenic or on corticosteroids.

Some series on $P$. aeruginosa have been published. In HIV-infected patients, this pathogen may cause not only nosocomial pneumonia but also communityacquired pneumonia or chronic bronchitis. Traditional risk factors for the development of $P$. aeruginosa infections such as neutropenia, steroids, previous antimicrobial treatment and recent hospitalisation were absent in most patients. Nevertheless, this infection occurred almost exclusively at the AIDS stage in patients with a very low level of CD4 T-lymphocytes [36, 38-40].

Opportunistic bacteria. Finally, opportunistic bacteria have also been incriminated, although to a lesser extent.

In short series, Nocardia spp. [41-44], Rhodococcus equi [45-48] and Streptomyces spp. [49] were found to be responsible for chronic pneumonia in AIDS patients.

Pasteurella multocida [50], Bordetella bronchiseptica [51, 52], Neisseria spp. [53], Rochalimaea spp. [54] Corynebacterium pseudodiphteriticum [55] and nonserotype 1 legionella [56] were equally the cause of pneumonia in case reports of HIV-infected patients with a high level of immunosuppression.

Nontyphoid strains of salmonella should be considered separately. In the series of CASADO et al. [57], lung involvement was found in 18 of $51(35 \%)$ of AIDS individuals with salmonella bacteraemia, but definite salmonella pulmonary infection was diagnosed in only six of $51(12 \%)$. It is clear that not all respiratory diseases observed in patients with salmonella bacteraemia are due to this pathogen [11]. Nevertheless, in a series of $38 \mathrm{HIV}$-infected patients with documented salmonellosis, two had a lung abcess and/or empyema, with Salmonella enteritidis being isolated from blood, sputum and pleural effusion [58].

Nosocomial bacteria. Ultimately, if nosocomial pneumonia is considered, $P$. aeruginosa, $S$. aureus and Enterobacteriaceae were usually responsible [20, 37, 38], as in HIV-seronegative patients.

Clinical presentation and diagnostic management of lower respiratory tract infection

Typical clinical presentation. In the vast majority of cases, the clinical presentation of HIV-infected subjects with bacterial pneumonia is similar to that of HIVseronegative patients with community-acquired pneumonia. Onset is acute [59] or subacute [32] with fever, cough, purulent sputum, dyspnoea and chest pain. Physical examination reveals abnormalities [59], mainly crackles [37]. Unilateral alveolar opacities are the most frequent radiological abnormalities [16, 37, 59-62]. Laboratory evaluation usually shows a leucocytosis but leucopenia can occur. Serum lactate dehydrogenase levels are typically normal or mildly elevated [63]. Hypoxaemia may be present [37]. In the stepwise logistical analysis of TuMBARELLo et al. [16], the independent indicators of mortality were: CD4 T-cell levels $<100$ cells $\cdot \mathrm{mm}^{-3}$; arterial oxygen tension $\leqslant 9.3 \mathrm{kPa}$ $(\leqslant 70 \mathrm{mmHg}$ ); Karnofsky score $<50$; and neutrophil count $<1,000$ cells $\cdot \mathrm{mm}^{-3}$ [16]. In severe cases, sepsis syndrome associated with hypotension, coagulopathy and multiorgan dysfunction can develop.

In a retrospective chart review, SELWYN et al. [59] tried to differentiate PCP, bacterial pneumonia and tuberculosis on the basis of clinical characteristics at presentation. On regression analysis, independent predictors for bacterial pneumonia included rales on examination (OR 12.4), a chart mention of "toxic" appearance (OR 9.1), fever for $\leqslant 7$ days (OR 6.6) and lobar infiltrate (OR 5.8).

Nevertheless, there are four important differences between bacterial pneumonia occurring in HIVinfected patients and that in HIV-seronegative patients.

High frequency of bacteraemia. The first difference is the high frequency of bacteraemia in HIV-infected patients. In the prospective study of PloufFe et al. [64], the relative risk of pneumococcal bacteraemia among HIV-infected persons was 41.8 times that of controls aged 18-64 yrs. A similar increase in the incidence of pneumococcal bacteraemia was observed by GILKS 
et al. [65] in Africa. This high frequency is found in the great majority of series $[22,23,66,67]$, reaching $50 \%$ of bacterial pneumonia in the series of GIL SUAY et al. [68]. Bacteraemia occurred with this unusual frequency, whatever the pathogen, e.g. S. pneumoniae $[25,27,31$, 69], H. influenzae [21] S. aureus [21], Escherichia coli [21], P. aeruginosa [36-39] and even $R$. equi [47].

Unusual radiographic abnormalities. The second difference is the high frequency of unusual radiographic abnormalities. Magnenat et al. [70] reviewed the radiological features of 60 consecutive cases of bacterial pneumonia in HIV-infected patients. Forty-five per cent showed classic segmental or lobar alveolar consolidation patterns but $33(55 \%)$ showed a predominantly interstitial infiltrate, this interstitial infiltrate being diffuse in 21 cases. There was no significant difference in the radiographic patterns between AIDS- and HIV-infected patients. In other series, a high frequency of multilobar consolidation or of bilateral involvement with either patchy bronchopneumonia or alveolointerstitial infiltrates has also been reported $[16,22,35,37]$, particularly with $H$. influenzae [32]. In such cases, it might be difficult to distinguish bacterial pneumonia from opportunistic infections like PCP [70].

High rate of pleural effusions. The third difference is the high rate of pleural effusions associated with pneumonia. In the case controlled study of GIL SUAY et al. [68], the rate of pleural effusions was two-fold higher in HIV-infected patients. These pleural effusions were mainly due to $S$. aureus. Their clinical course was more indolent with a long duration of symptoms before hospitalisation and more severe with a high percentage of bacteraemia and an unusual need for drainage. In the same way, bacterial pneumonia was the condition most commonly associated with pleural effusions in the series of AfEssa [71]. Such pleural effusions have been found with typical bacteria [37], as well as opportunistic bacteria such as $N$. asteroides [46] or R. equi [44].

Bacterial pneumonia due to opportunistic bacteria. The last difference concerns the unusual presentation of cases of bacterial pneumonia due to opportunistic bacteria, particularly $N$. asteroides and $R$. equi. The most frequent clinical and radiological features at presentation are subacute onset (median duration of symptoms prior to presentation frequently $>1$ month), respiratory symptoms, fever, weight loss and fatigue, lung consolidation or cavitary lesions. Extrapulmonary localisation, such as in pericardial effusion or a brain abcess, may be present at the time of presentation $[44,46]$.

Diagnostic management of lower respiratory tract infection. In practice, the clinical hypotheses and diagnostic approach clearly depend on clinical presentation and degree of immunosuppression. It is possible to distinguish between four schematic situations [72].

In the first situation, the clinical features are those of classic bacterial pneumonia with acute onset in an HIV-infected patient with a CD4 T-cell count of $>200$ cells $\cdot \mathrm{mm}^{-3}$. The pathogens responsible are typical bacteria, mainly $S$. pneumoniae. In all cases, emergency treatment, including a $\beta$-lactam antibiotic effective against $S$. pneumoniae, should be started after blood culture. In cases with acute respiratory failure, fibreoptic bronchoscopy with protected bronchial brushing might be useful.

The second situation, defined by subacute progression of the condition, fever and diffuse opacities in a patient with a CD4 T-cell count of $<200$ cells $\cdot \mathrm{mm}^{-3}$, usually indicates an opportunistic pneumonia, such as PCP, but, in AIDS patients, typical bacteria and particularly $H$. influenzae might also be the cause. In all cases, fibreoptic bronchoscopy with BAL [73] and protected bronchial brushing is indicated [70]. This should be performed before starting empirical treatment [74].

The third situation with subacute or moderate progression of the condition, fever, weight loss, nodules [75] or alveolar infiltrates, with or without cavitation [76], in a patient with a CD4 T-cell count of $<100$ cells $\cdot \mathrm{mm}^{-3}$, usually indicates an opportunistic infection due to mycobacteria, fungus, Nocardia spp. or $R$. equi, but $S$. aureus, members of the Enterobacteriaceae family or $P$. aeruginosa might also be responsible. In this situation, fibreoptic bronchoscopy with BAL and protected bronchial brushing or transthoracic needle aspiration [77] is indicated in all cases. Ideally, this should be performed after computed tomography (CT) to provide guidance regarding the optimal type and risk of sampling. After a negative first-line procedure including BAL, a second BAL combined with transbronchial biopsy allowed a definitive diagnosis in $90 \%$ of cases with nodules or focal infiltrates [78].

The last situation concerns HIV-infected patients with chronic sinusitis and chronic bronchitis. Such symptoms or signs usually occur in patients with lymphoid interstitial pneumonia or advanced HIV disease. Sinus and thoracic CT scans are of interest. Microbiological documentation is useful in guiding the choice of antibiotics.

\section{Course of bacterial lower respiratory tract infection}

Short-term mortality. In the majority of series of bacterial pneumonia in HIV-infected patients, the shortterm mortality was the same as in HIV-seronegative subjects. In the series of 49 episodes of communityacquired lobar pneumonia of MiLLER et al. [67], 13 episodes were complicated by pleural effusion or empyema and 11 by lung cavitation. In this series, in spite of an unusual rate of complications, the mortality rate was only $8 \%$. Many other series with $S$. pneumoniae [22, 28], H. influenzae [32], L. pneumophila [33] and other typical pathogens [37] have also shown a percentage of deaths similar to that usually observed in HIV-seronegative people. However, the bacteraemia level and mortality increase with the progression of HIV disease. This is clear for pneumonia due to $P$. aeruginosa $[16,36]$ or other opportunistic bacteria [44] observed exclusively at the AIDS stage. This is also true for pneumococcal pneumonia complicated by 
bacteraemia, the mortality clearly being higher in the subgroup of AIDS patients [79].

In patients cured of their acute episode of bacterial pneumonia, two late unfavourable events might occur: recurrence of LRTI and decrease in survival time.

High rate of recurrence. In the absence of immune restoration, obvious recurrence was observed in cases of opportunistic bacterial pneumonia, e.g. those due to $R$. equi $[47,48]$ or $N$. asteroides [44] needing a very prolonged period of curative treatment $[44,47]$. Nevertheless, recurrence has also been observed with typical bacterial pneumonia. In the cohort study of GiLKs et al. [10], a first episode of bacterial pneumonia was observed in 54 patients during a 36-month follow-up. During this relatively short follow-up period, a first recurrence of bacterial pneumonia occurred in $24 \%$ of cases, which is the very high recurrence rate usually reported for HIV-infected patients [22, 28, 69, 76]. The recurrence might be due to the same or a new pathogen [80].

Such recurrence has also been observed for bacterial bronchitis and mainly described for $H$. influen$z a e$ and $P$. aeruginosa. With this latter organism, the patients were at a late stage of their HIV disease and suffered from repeated exacerbations of chronic bronchitis needing repeated antibiotic treatment. In spite of antibiotic therapy, $P$. aeruginosa persisted. When performed, serial CT scans showed a course towards bronchiectasis, as seen in patients with cystis fibrosis [40]. It should be noted that such bronchiectasis has been particularly well described in HIVinfected children [81].

Decrease in survival time. In a recent case controlled study, Osmond et al. [82] compared the survival time of patients that had recovered from their bacterial pneumonia or PCP and two control subjects matched by CD4 T-lymphocyte count. On multivariate analysis, the occurrence of the PCP or bacterial pneumonia was a highly significant predictor of shorter survival time [82]. The differences between cases and controls were not due to early mortality after initial diagnosis.

There are two main explanations for this shorter survival time [83]. 1) It is known that bacterial pneumonia increases local [84, 85] and systemic [86] HIV replication. Consequently, bacterial pneumonia might accelerate the progression of HIV disease. 2) Bacterial pneumonia could be a single marker of more severe immunodepression than is reflected in the CD4 T-cell count.

In addition, in a recent study, MorRIS et al. [87] showed that bacterial pneumonia, as well as PCP, resulted in expiratory airflow reductions that persisted after the acute infection resolved. These changes might contribute to prolonged respiratory complaints in HIV-infected patients who have had pneumonia.

\section{Host defence deficiencies incriminated}

Abnormalities in host defences caused by HIV infection are probably present early on in the course of the illness and increase in severity with the duration of infection. If the defects in cell-mediated immunity play a central role in opportunistic infections [88], the resulting local and systemic defects in humoral immunity play the major role in bacterial pneumonia [89-93].

Other defects [94], such as nonspecific host defencelike dysfunction of phagocytes [95, 96], abnormal activation of the complement system, alterations in hepatic and splenic clearance, alteration of surfactant and a low mannose-binding lectin serum concentration [97] have also been incriminated.

\section{Human immunodeficiency virus-infected patients receiving prophylaxis for pulmonary infections but not antiretroviral treatment}

In the past, this was the situation of the majority of patients in developed countries. Currently, this is the situation of the majority of patients in developing countries.

\section{Changes in the incidence of bacterial pneumonia in the} era of prophylaxis.

A first approach to studying these changes is to consider the period around 1990, as, at this time, HIVinfected patients had access to prophylaxis but not to HAART. For example, LyON et al. [98] compared autopsy findings from before 1984 with those after 1989. During the earlier time period, PCP was more prevalent and was the major cause of death. During the latter time period, as prophylaxis was mainly effective against PCP, bacterial infection, predominantly bronchopneumonia due to $S$. aureus or $P$. aeruginosa, became most frequent and the major cause of death. STEIN et al. [99] also found that, between January 1988 and July 1990, bacterial infections were the most common cause of death $(30 \%)$, whereas PCP was responsible for only $16 \%$ of deaths. Finally, AfESSA et al. [100] showed that, during the period 1985-1996, of all pulmonary complications found at autopsy, only the incidence of PCP decreased.

Another approach to investigating these changes may be through cohort studies. Hoover et al. [101] clearly showed that $M$. avium-intracellulare disease, oesophageal candidiasis, wasting syndrome and cytomegalovirus disease were more common in HIVinfected patients who had received prophylaxis against $P$. carinii than in those who had not. Unfortunately, bacterial pneumonia and recurrent bacterial pneumonia were not mentioned.

A last approach is to observe the changes in the causes of respiratory diseases requiring hospitalisation of HIV-infected patients. In the UK, PITKIN et al. [102] noted a decrease in the relative frequency of PCP $(68 \%$ of admissions in 1986-1987 and 48\% in 1990-1991) and an increase in that of bacterial infections $(14 \%$ of admissions in 1986-1987 and 23\% in 1990-1991). During the same period, similar changes were also found in the present author's department, where the relative frequency of PCP was reduced two-fold (40\% in 1980-1985 and 24\% in 1990-1993) and that of 
bacterial pneumonia increased three-fold $(8 \%$ in 1980-1985 and 25\% in 1990-1993) (data not shown).

It is very difficult, from these studies, to determine the respective role played by each prophylactic treatment recommended and the first antiretroviral drugs, such as zidovudine, in these changes [103]. Consequently, the preventive effectiveness of each prophylactic treatment should be considered separately. In the current review, tobacco cessation, vaccination against $H$. influenzae $\mathrm{b}$, recommended for HIVinfected children, prophylactic antibiotics in cases of repeated recurrence of severe bacterial LRTI and intravenous immunoglobulin, which may be useful in preventing serious bacterial infections in HIV-infected children, are only mentioned in passing [104, 105].

\section{Effectiveness of pneumococcal vaccine}

In the US guidelines [106], pneumococcal vaccine is indicated in all patients with a moderate level of immunosuppression. Indeed, previous studies have clearly shown that some asymptomatic HIV-infected patients and, more particularly, those with a CD4 T-lymphocyte count of $>500$ cells $\cdot \mathrm{mm}^{-3}$, developed appropriate antibody responses to the 23-valent pneumococcal vaccine [107-110].

Effectiveness of pneumococcal vaccine in developed countries. Two retrospective case controlled studies and one observational cohort study are available to illustrate the effectiveness of pneumococcal vaccine in developed countries.

In the first retrospective case controlled study, GUERRERo et al. [111] found that pneumococcal immunisation was associated with a reduction in the risk of pneumonia of almost $70 \%$. This result was obtained even when immunisation was given with a CD4 T-cell count of $<100$ cells $\cdot \mathrm{mm}^{-3}$.

In the second retrospective case controlled study, the pneumococcal vaccine's effectiveness in preventing invasive pneumococcal disease was 50\% $(95 \%$ confidence interval $12-70 \%$ ) after adjustment for CD4 T-cell count [112]. However, it should be noted that, in the group of HIV-infected patients of African origin, the pneumococcal vaccine was not significantly effective. This failure to demonstrate effectiveness among Blacks might be due to limited power because of limited use of the vaccine in this population, immunisation at more advanced stages of immunosuppression or unmeasured factors.

Finally, in a US observational cohort study among 40,000 HIV-infected persons, pneumococcal vaccine was also effective in preventing pneumococcal disease [113]. This effectiveness was strongly related to the level of immunosuppression at the time of vaccination. A significant decrease in incidence was observed only for invasive pneumococcal disease and only in patients in whom pneumococcal vaccination had been performed at a CD4 lymphocyte count of $>500$ cells $\cdot \mathrm{mm}^{-3}$. In the same cohort, pneumococcal vaccination was associated with slightly improved survival compared with persons who had not received pneumococcal vaccination [103].
Effectiveness of pneumococcal vaccine in developing countries. FRENCH et al. [114] evaluated the effectiveness of pneumococcal vaccine in a prospective randomised trial in a cohort of HIV-infected Ugandans. Surprisingly, the vaccine was ineffective in the prevention of invasive as well as noninvasive pneumococcal disease, including those due to the serotypes included in the vaccine. Moreover, the vaccine appeared to increase the risk of developing pneumonia, whatever its cause. This lack of vaccine efficacy might be related to impaired production of capsule-specific immunoglobulin G [115]. However, this poor response would not explain the detrimental effect of immunisation. One possible hypothesis is transient upregulation of HIV1 transcription, but there was no association between immunisation and serious infections other than pneumonia and death. Another possible hypothesis is a direct harmful effect of pneumococcal polysaccharides by destruction of polysaccharide-responsive B-cell clones. This effect might explain in part the high recurrence rate of pneumococcal disease seen in HIVinfected patients [114].

Today, the effectiveness, and even safety, of pneumococcal vaccination in HIV-infected persons in Africa remains debatable.

Effectiveness of anti-infectious drugs recommended for prophylactic treatment of opportunistic infections

Effectiveness of anti-infectious drugs in developed countries. In developed countries, United States Public Health Service/Infectious Diseases Society of America guidelines recommend cotrimoxazole (trimethoprim/ sulfamethoxazole) in HIV-infected patients with a CD4 T-cell count of $<200$ cells $\cdot \mathrm{mm}^{-3}$ to prevent PCP, and clarithromycin or azithromycin in HIV-infected patients with a CD4 T-cell count of $<50$ cells $\cdot \mathrm{mm}^{-3}$ to prevent $M$. avium complex disease [106]. Thus, in some prospective [116] or case controlled [117] studies of PCP or $M$. avium complex prophylaxis, the use of cotrimoxazole or macrolides was associated with a low incidence of bacterial infection, although with a lesser efficacy if given as secondary prophylaxis [118]. Similarly, in the retrospective cohort study of BUSKIN et al. [119], cotrimoxazole reduced the risk of major infections. Moreover, in this last study, cotrimoxazole also reduced the risk of death not attributable to PCP. Finally, in a recent prospective study, CURrier et al. [120] evaluated the indirect effectiveness of anti-infectious drugs given to prevent opportunistic infections in patients with a CD4 lymphocyte count of $<200$ cells $\cdot \mathrm{mm}^{-3}$ using multivariate analysis. Four regimens were effective at preventing bacterial infections: cotrimoxazole, clarithromycin, a combination of clarithromycin and rifabutin, and, finally, a combination of cotrimoxazole and clarithromycin. Nevertheless, it should be pointed out that, as for pneumococcal vaccine, the effectiveness remained limited.

Effectiveness of anti-infectious drugs in developing countries. Since the effectiveness and safety of pneumococcal vaccine were questionable in Central Africa, it was logical that alternative strategies for the 
prevention of bacterial infections be considered. Thus, the World Health Organization (WHO) and the Joint United Nations Programme on HIV/AIDS have recently recommended the use of cotrimoxazole prophylaxis for HIV-infected adults in Africa with symptomatic HIV disease (stage 2, 3 or 4 of the WHO classification of HIV infection and disease) and for asymptomatic individuals with a CD4 T-cell count of $<500$ cells $\cdot \mathrm{mm}^{-3}$ [121]. Indeed, the beneficial effect of cotrimoxazole has been evaluated in Abidjan, Ivory Coast, in two recent prospective randomised trials. In the first study, by ANGLARET et al. [122], cotrimoxazole was administered to HIV-infected patients when in clinical stage 2 or 3 of the WHO classification. At 12 months, there was a significant decrease in hospital admissions, mainly those due to bacterial pneumonia, malaria and unexplained fever, in patients receiving cotrimoxazole. In the second study, by WIKTOR et al. [123], cotrimoxazole was administered to HIV-infected patients treated for tuberculosis with positive smears. There was a significant decrease in hospital admissions, mainly those due to septicaemia or enteritis. Also, as in the study of BusKIN et al. [119], there was a significant decrease in mortality, particularly among patients with a CD4 T-cell count of $<350$ cells $\cdot \mathrm{mm}^{-3}$.

Nevertheless, two questions remain unresolved. 1) Which patients are likely to benefit from cotrimoxazole? In a recent observational cohort study, BADRI et al. [121] showed that cotrimoxazole reduced mortality and the incidence of severe HIV-related illnesses in patients with evidence of advanced immune suppression on clinical (WHO stage 3 and 4) or laboratory (CD4 count $<200$ cells $\cdot \mathrm{mm}^{-3}$ ) assessment. In this study, no significant evidence of effectiveness was found in patients with WHO stage 2 disease or a CD4 count of $200-500$ cells $\cdot \mathrm{mm}^{-3}$. 2) What is the long-term risk of raising the cotrimoxazole resistance of typical bacteria? A recent study in the San Francisco (CA, USA) area partly answers this last question. In the HIV units in this area, the frequency of cotrimoxazole-resistant bacteria has recently increased. This increase coincided temporally with an increase in the prophylactic use of cotrimoxazole in HIV-infected patients. Finally, the frequency of cotrimoxazoleresistant bacteria has also increased in non-HIV units and cotrimoxazole resistance was associated with multidrug resistance [124].

\section{Effect of prophylaxis on clinical presentation of bacterial pneumonia}

In the recent review of SEPKOwITz [125] on the effect of prophylactic treatment on recent clinical manifestations of AIDS-related opportunistic infections, no change concerning bacterial pneumonia was reported. The only reported changes were in the relative frequencies of responsible bacteria. Thus, pneumococcal vaccine specifically reduced the incidence of pneumococcal pneumonia. In the same way, in the recent cohort study of DwORKIN et al. [126], multivariate analysis showed that prescription of cotrimoxazole was associated with significant protection against Haemophilus spp., staphylococcal infection (invasive or any), but not against pneumococcal or nonpneumococcal Streptococcus, Klebsiella or Pseudomonas spp. infections.

\section{Human immunodeficiency virus-infected patients receiving highly active antiretroviral therapy, with or without prophylaxis of opportunistic infections}

This is the situation of the great majority of HIVinfected patients in developed countries who receive HAART and prophylactic treatment of opportunistic infections until a CD 4 cell count of $>200$ cells $\cdot \mathrm{mm}^{-3}$ is reached [127-129]. Effect of highly active antiretroviral therapy on
incidence of bacterial pneumonia

In a German cohort, during 1992-1996, BRODT et al. [130] observed a significant decrease in the number of cases of bacterial pneumonia, clearly related to the number of antiretroviral drugs administered. Similarly, in the important US cohort study of DwORKIN et al. [113], antiretroviral treatment was an independent factor that contributed to a two-fold decrease in the incidence of pneumococcal disease during 1990-1998. As in the study of BRODT et al. [130], the protective effect increased with the number of antiretroviral drugs and the resulting antiretroviral effectiveness.

This significant reduction was not observed in the outstanding French clinical epidemiology database in which the decreases in both incidence $(<20 \%)$ and recurrence $(<40 \%)$ of bacterial pneumonia were relatively low during 1992-1999 [26]. In this database, this slight variation contrasted with the dramatic decrease observed for opportunistic infections such as PCP, cytomegalovirus infection or toxoplasmosis. Finally, Tumbarello et al. [131] also observed a decrease in the incidence of bacterial pneumonia in the era of HAART, but this decrease was principally observed for nosocomial pneumonia and remained nonsignificant for community-acquired pneumonia.

Indirect approaches might also be considered for the evaluation of these changes.

One approach is to consider the impact of HAART on the characteristics of HIV-infected patients hospitalised during 1995-1997. During this period, PAul et al. [132] observed a two-fold decrease in the incidence of hospital admissions for HIV-infected patients but, in 1997, bacterial pneumonia remained the most common diagnosis at admission.

A second approach is to consider the impact of HAART on the causes of death in the HIV-infected population. MASLIAH et al. [133] recently analysed the changes in pathological findings at autopsy in AIDS cases over the last 15 yrs. Overall, the frequency of opportunistic infections decreased, whereas that of bacterial infections increased, with the lung remaining the organ most frequently involved. These results were in accordance with those of AFEssA et al. [100], who found that, in 1996, bacterial pneumonia remained the most frequent pulmonary complication at autopsy of persons with AIDS. 
A last approach is to compare the causes of respiratory disease in HIV-infected patients hospitalised in a chest department before and after 1997, which was the first year in which there was widespread routine HAART use. In the present author's chest department, the absolute number of bacterial LRTIs decreased between the periods 1993-1996 and 19971999 , but its relative frequency was similar (data not shown).

Effect of highly active antiretroviral therapy on clinical presentation of bacterial pneumonia

Currently, it is clear that rapid restoration of cellular immunity due to HAART may induce a transitory increase in the symptoms and signs of opportunistic pneumonia [134], such as tuberculosis [135] or PCP [136].

To the best of the present author's knowledge, this transitory exacerbation has not been reported for bacterial pneumonia. The main change observed in the French epidemiological database is that, in 1999, bacterial pneumonia occurred at a lesser degree of immunosuppression than in 1992. In 1992, $>50 \%$ of bacterial pneumonia occurred in patients with $<50$ CD4 T-cells $\cdot \mathrm{mm}^{-3}$. This percentage fell to $<20 \%$ in 1999 [26].

One expected consequence of this occurrence at a lesser degree of immunosuppression was a change in the responsible pathogens. In the present author's chest department, the relative frequencies of both $S$. pneumoniae and $H$. influenzae increased in the period 1996-1999 compared with the period 19931996. In contrast, no pneumonia or bronchiectasis due to $P$. aeruginosa has been observed since 1996 (data not shown). Thus, Domingo et al. [40] reported the definite cure of $P$. aeruginosa LRTI in patients receiving effective HAART.

\section{The way forward}

Even though the incidence of opportunistic LRTI is decreasing during the current era of HAART, bacterial pneumonia remains, in 2002, the most frequent respiratory disease in all subgroups of HIV-infected patients: 1) those without knowledge of their HIVseropositivity, in whom typical bacterial pneumonia may reveal the HIV infection [69]; 2) those without follow-up or noncompliant with treatment [137], in whom typical as well as opportunistic bacterial pneumonia may be observed; 3 ) those receiving effective antiretroviral treatment, in whom bacterial pneumonia remains the major cause of respiratory disorders, as previously discussed; and 4) those receiving ineffective antiretroviral treatment (because of acquired resistance to HIV), in whom typical, opportunistic and nosocomial bacterial pneumonia still occur.

If it is borne in mind that bacterial infection remains the leading cause of death at the pre-acquired immune deficiency syndrome stage [138] and the most frequent terminal event in human immunodeficiency virus-infected patients [100], it is clear that their prevention remains a major goal. Thus, pneumococcal vaccination might be given to the patient on highly active antiretroviral therapy with a CD4 cell count reaching 200 cells $\cdot \mathrm{mm}^{-3}$.

Acknowledgements. The authors thank P. Yvernault and M. Dabancourt for their technical assistance.

\section{References}

1. Murray J, Felton C, Garay S, et al. Pulmonary complications of the acquired immunodeficiency syndrome. N Engl J Med 1984; 310: 1682-1685.

2. Stover D, White D, Romano P, Gellene R, Robeson W. Spectrum of pulmonary diseases associated with the acquired immune deficiency syndrome. Am J Med 1985; 78: 429-437.

3. Murray J, Mills J. Pulmonary infectious complications of human immunodeficiency virus infection (part I). Am Rev Respir Dis 1990; 141: 1356-1372.

4. Mitchell D, Miller F. New developments in the pulmonary diseases affecting HIV-infected patients. Thorax 1995; 50: 294-302.

5. Noskin G, Glassroth J. Pulmonary infections in HIV1 infected patients. Eur Respir Mon 1995; 2: 255-285.

6. Mayaud C, Cadranel J. AIDS and the lung in a changing world. Thorax 2001; 56: 423-426.

7. Wallace JM, Hansen N, Lavange L, et al. Respiratory disease trends in the pulmonary complications of HIV-infection study cohort. Am J Respir Crit Care Med 1997; 155: 72-80.

8. Caiaffa W, Vlahov D, Graham N, et al. Drug smoking, Pneumocystis carinii pneumonia, and immunosuppression increase risk of bacterial pneumonia in human immunodeficiency virus-seropositive injection drug-users. Am J Respir Crit Care Med 1994; 150: 1493-1498.

9. Boschini A, Smacchia C, Di Fine M, et al. Community-acquired pneumonia in a cohort of former injection drug users with and without human immunodeficiency virus infection: incidence, etiologies, and clinical aspects. Clin Infect Dis 1996; 23: 107-113.

10. Gilks C, Ojoo S, Ojoo J, et al. Invasive pneumococcal disease in a cohort of predominantly HIV1-infected female sex workers in Nairobi. Lancet 1996; 347: 718723.

11. Kamanfu G, Mlika-Cabanne N, Girard PM, et al. Pulmonary complications of human immunodeficiency virus infection in Bujumbura, Burundi. Am Rev Respir Dis 1993; 147: 658-663.

12. Daley C, Mugusi F, Chen L, et al. Pulmonary complications of HIV infection in Dar es Salaam, Tanzania. Am J Respir Crit Care Med 1996; 154: 105110.

13. Scott J, Hall A, Muyodi C, et al. Aetiology, outcome and risk factors for mortality among adults with acute pneumonia in Kenya. Lancet 2000; 355: 1225-1230.

14. Wallace J, Rao V, Glassroth J, et al. Respiratory illness in persons with human immunodeficiency virus infection. Am J Respir Crit Care Med 1993; 148: 15231529.

15. Hirschtick R, Glassroth J, Jordan M, et al. Bacterial pneumonia in persons infected with the human 
immunodeficiency virus. $N$ Engl J Med 1995; 333: 845851.

16. Tumbarello M, Tacconelli E, de Gaetano, et al. Bacterial pneumonia in HIV-infected patients: analysis of risk factors and prognostic indicators. $J$ Acquir Immune Defic Syndr 1998; 18: 39-45.

17. Moore R, Keruly J, Chaisson R. Neutropenia and bacterial infection in acquired immunodeficiency syndrome. Arch Intern Med 1995; 155: 1965-1970.

18. Kemeny M, Cooke V, Melester T, et al. Splenectomy in patients with AIDS and AIDS-related complex. AIDS 1993; 7: 1063-1067.

19. Genet P, Lionnet F, Pulik M, Petitdidier C, Le Turdu F. Severe pneumococcal infections in splenectomized HIV-positive patients. AIDS 1994; 8: 850-851.

20. Tumbarello M, Tacconelli E, de Gaetano Donati K, et al. Nosocomial bacterial pneumonia in human immunodeficiency virus infected subjects: incidence, risk factors and outcome. Eur Respir J 2001; 17: 636640.

21. Madhi S, Petersen K, Madhi A, Khoosal M, Klugman $\mathrm{K}$. Increased disease burden and antibiotic resistance of bacteria causing severe community-acquired lower respiratory tract infections in human immunodeficiency virus type 1 -infected children. Clin Infect Dis 2000; 31: 170-176.

22. Polsky B, Gold J, Whimbey E, et al. Bacterial pneumonia in patients with the acquired immunodeficiency syndrome. Ann Intern Med 1986; 104: 38 41.

23. Whimbey E, Gold J, Polsky B, et al. Bacteremia and fungemia in patients with the acquired immunodeficiency syndrome. Ann Intern Med 1986; 104: 511-514.

24. Mayaud C, Touboul J, Delisle-Mizon F, Vergez P, Akoun G. Bronchopneumopathies bactériennes chez les malades atteints de syndrome d'immunodépression acquise. Presse Med 1986; 15: 760-761.

25. Witt D, Craven D, McCabe W. Bacteremial infections in adults patients with the acquired immune deficiency syndrome (AIDS) and AIDS-related complex. Am J Med 1987; 82: 900-906.

26. Abgrall S, Benoliel S, Costagliola D, Grabar S, Lievre L, Mary-Krause M. Retour d'informations clinico-épidémiologiques. No. 8. Centre coopérateur de données épidémiologiques sur l'immunodéficience humaine [B3 ${ }^{\mathrm{E}}$-INSERM SC4]. 2000.

27. Jones N, Huebner R, Khoosal M, Crewe-Brown H, Klugman K. The impact of HIV on Streptococcus pneumoniae bacteraemia in a South African population. AIDS 1998; 12: 2177-2184.

28. Frankel R, Virata M, Hardalo C, Altice F, Friedland G. Invasive pneumococcal disease: clinical features, serotypes and antimicrobial resistance patterns in cases involving patients with and without human immunodeficiency infection. Clin Infect Dis 1996; 23: 577-584.

29. Bedos J, Chevret S, Chastang C, Geslin P, Regnier B, and the French Cooperative Pneumococcus Study Group. Epidemiological features of and risk factors for infection by Streptococcus pneumoniae strains with diminished susceptibility to penicillin: findings of a French survey. Clin Infect Dis 1996; 22: 63-72.

30. Mao $\mathrm{C}$, Harper $\mathrm{M}$, McIntosh $\mathrm{K}$, et al. Invasive pneumococcal infections in human immunodeficiency virus-infected children. $J$ Infect Dis 1996; 173: 870876.
31. Afessa B, Green B. Bacterial pneumonia in hospitalized patients with HIV infection. Chest 2000; 117: 1017-1022.

32. Cordero E, Pachon J, Rivero A, Giron J, ComezMateos J, Merino M. Haemophilus influenzae pneumonia in human immunodeficiency virus-infected patients. Clin Infect Dis 2000; 30: 461-465.

33. Blatt S, Dolan M, Hendrix C, Melcher G. Legionnaires' disease in human immunodeficiency virusinfected patients: eight cases and review. Clin Infect Dis 1994; 18: 227-232.

34. Dalhoff K, Maass M. Chlamydia pneumoniae pneumonia in hospitalized patients. Chest 1996; 110: 351356.

35. Levine $\mathrm{S}$, White $\mathrm{D}$, Fels $\mathrm{A}$. The incidence and significance of Staphylococcus aureus in respiratory cultures from patients infected with the human immunodeficiency virus. Am Rev Respir Dis 1990; 141: 89-93.

36. Schuster M, Norris A. Community-acquired Pseudomonas aeruginosa pneumonia in patients with HIV infection. AIDS 1994; 8: 1437-1441.

37. Baril L, Astagneau $\mathrm{P}$, Nguyen $\mathrm{J}$, et al. Pyogenic bacterial pneumonia in human immunodeficiency virus-infected patients: a clinical, radiological, microbiological, and epidemiological study. Clin Infect Dis 1998; 26: 964-971.

38. Fichtenbaum C, Woeltje K, Powderly W. Serious Pseudomonas aeruginosa infections in patients infected with human immunodeficiency virus. A case-control study. Clin Infect Dis 1994; 19: 417-422.

39. Mendelson M, Gurtman A, Szabo S, et al. Pseudomonas aeruginosa bacteria in patients with AIDS. Clin Infect Dis 1994; 18: 886-895.

40. Domingo P, Ferre A, Baraldes M, Ris J, Sanchez F. Pseudomonas aeruginosa bronchopulmonary infection in patients with AIDS, with emphasis on relapsing infection. Eur Respir J 1998; 12: 107-112.

41. Holtz H, Lavery D, Kapila R. Actinomycetales infection in the acquired immunodeficiency syndrome. Ann Intern Med 1985; 102: 203-205.

42. Rodriguez J, Barrio J, Pitchenik A. Pulmonary nocardiosis in the acquired immunodeficiency syndrome. Chest 1986; 90: 912-914.

43. Desfemmes T, Cadranel J, Delisle F, Akoun G, Mayaud C. Nocardiose pulmonaire et cérébrale chez un patient infecté par le VIH. Rev Mal Respir 1993; 10: 262-264.

44. Uttamchandani R, Daikos G, Reyes R, et al. Nocardiosis in 30 patients with advanced human immunodeficiency virus infection: clinical features and outcome. Clin Infect Dis 1994; 18: 348-353.

45. Samies J, Hathaway B, Echols R, Veazey J, Pilon V. Lung abscess due to Corynebacterium equi. $\mathrm{Am} \mathrm{J} \mathrm{Med}$ 1986; 80: 685-688.

46. Verville T, Huycke M, Greenfield R, Fine D, Kuhls T, Slater G. Rhodococcus equi infections of humans. Medicine 1994; 73: 119-132.

47. Donisi A, Suardi M, Casari S, Longo M, Cadeo G, Carosi G. Rhodococcus equi infection in HIV-infected patients. AIDS 1996; 10: 359-362.

48. Giacometti A, Cirioni O, Burzacchini $\mathrm{F}$, et al. Rhodococcus equi infections: antibiotic therapy and relapses. AIDS 1997; 11: 120-121.

49. Dunne E, Burman W, Wildon M. Streptomyces pneumonia in a patient with human immunodeficiency virus infection: case report and review of the literature 
in invasive Streptomyces infections. Clin Infect Dis 1998; 27: 93-96.

50. Drabick J, Gasser R, Saunders N, et al. Pasteurella multocida pneumonia in a man with AIDS and nontraumatic feline exposure. Chest 1993; 103: 7-11.

51. De la Fuente J, Aibo C, Rodriguez A, Sopena B, Martinez C. Bordetella bronchiseptica pneumonia in a patient with AIDS. Thorax 1994; 49: 719-720.

52. Brisou P, De Jaure Guiberry J, Peyrade F, Muzellec Y, Jaubert D. Sinusite et pneumopathie à Bordetella bronchiseptica au cours du SIDA. Presse Med 1994; 23: 1400.

53. Morla N, Guidourdenche M, Riou J. Neisseria spp and AIDS. J Clin Microbiol 1992; 30: 2290-2294.

54. Koehler J, Tappero J. Bacillary angiomatosis and bacillary peliosis in patients infected with human immunodeficiency virus. Clin Infect Dis 1993; 17: 612 624.

55. Cohen Y, Force G, Gros I, Canzi AM, Lecleach L, Dreyfuss D. Corynebacterium pseudodiphtheriticum pulmonary infection in AIDS patients. Lancet 1992; 340: 114-115

56. Harris A, Lally M, Albrecht M. Legionella bozemanii pneumonia in three patients with AIDS. Clin Infect Dis 1998; 27: 97-99.

57. Casado J, Navas E, Frutos B, et al. Salmonella lung involvement in patients with HIV infection. Chest 1997; 112: 1197-1201.

58. Guerrero M, Ramos J, Nunez A, Cuenca M, de Gorgolas M. Focal infections due to non-typhi Salmonella in patients with AIDS: report of 10 cases and review. Clin infect Dis 1997; 25: 690-697.

59. Selwyn P, Pumerantz A, Durante A, et al. Clinical predictors of Pneumocystis carinii pneumonia, bacterial pneumonia and tuberculosis in HIV-infected patients. AIDS 1998; 12: 885-893.

60. De Truchis P, Cadranel J, Touboul J, et al. Fréquence respective et aspects radiocliniques de 150 pneumopathies observées chez 125 malades infectés par le virus de l'immunodéficience humaine. Presse Med 1988; 17: 781-785.

61. Naidich D, Garay S, Leitman B, McCauley D. Radiographic manifestations of pulmonary disease in the acquired immunodeficiency syndrome (AIDS). Semin Roentgenol 1987; 22: 14-30.

62. Carette MF, Mayaud C, Bigot J. Pulmonary and mediastinal involvement in AIDS. In: Trotot PM, ed. Imaging of AIDS. B.C. Decker, Inc., Philadelphia, 1991; pp. 25-56.

63. Boldt M, Bai T. Utility of lactate deshydrogenase vs radiographic severity in the differential diagnosis of Pneumocystis carinii pneumonia. Chest 1997; 111: 1187-1192.

64. Plouffe J, Breiman R, Facklam R. Bacteremia with Streptococcus pneumoniae. JAMA 1996; 275: 194-198.

65. Gilks C, Brindle R, Otieno L, et al. Life-threatening bacteraemia in HIV-1 seropositive adults admitted to hospital in Nairobi, Kenya. Lancet 1990; 336: 545 549.

66. Krumholz H, Sande M, Lo B. Community-acquired bacteremia in patients with acquired immunodeficiency syndrome: clinical presentation, bacteriology and outcome. Am J Med 1989; 86: 776-779.

67. Miller R, Foley N, Kessel D, Jeffrey A. Community acquired lobar pneumonia in patients with HIVinfection and AIDS. Thorax 1994; 49: 367-368.

68. Gil Suay V, Cordero $\mathrm{P}$, Martinez E, et al.
Parapneumonic effusions secondary to communityacquired bacterial pneumonia in human immunodeficiency virus-infected patients. Eur Respir J 1995; 8: $1934-1939$

69. Duval X, Paty M, Longuet P, et al. Pneumopathies dues à Streptococcus pneumoniae chez 27 malades infectés par le VIH. Presse Med 1995; 24: 715-718.

70. Magnenat J, Nicod L, Auckenthaler R, Junod A. Mode of presentation and diagnosis of bacterial pneumonia in human immunodeficiency virus-infected patients. Am Rev Respir Dis 1991; 144: 917-922.

71. Afessa N. Pleural effusion and pneumothorax in hospitalized patients with HIV infection. Chest 2000; 117: 1031-1037.

72. Mayaud C, Denis M, Nahmias G, $\mathrm{H}^{\prime}$ Moud T, Akoun G. Respiratory involvements during HIV infection: a diagnostic and therapeutic strategy. Bull Int Union Tuberc Lung Dis 1988; 63: 27-31.

73. Stover D, White D, Romano P, Gellene R. Diagnosis of pulmonary disease in acquired immune deficiency syndrome. Am Rev Respir Dis 1984; 130: 659-662.

74. De Gracia J, Miravitlles M, Mayordomo C, et al. Empiric treatments impair the diagnostic yield of BAL in HIV-positive patients. Chest 1997; 111: 1180-1186.

75. Jasmer R, Edinburgh K, Thompson A, et al. Clinical and radiographic predictors of the etiology of pulmonary nodules in HIV-infected patients. Chest 2000; 117: 1023-1030.

76. Furman A, Jacobs J, Sepkowitz K. Lung abscess in patients with AIDS. Clin Infect Dis 1996; 22: 81-85.

77. Falguera M, Nogues A, Ruiz-Gonzales A, Garcia M, Puig T, Rubio-Caballero M. Transthoracic needle aspirations in the study of pulmonary infections in patients with HIV. Chest 1994; 106: 697-702.

78. Cadranel J, Gillet Juvin K, Antoine M, et al. Sitedirected bronchoalveolar lavage and transbronchial biopsy in HIV-infected patients with pneumonia. $\mathrm{Am}$ J Respir Crit Care Med 1995; 152: 1103-1106.

79. Pesola G, Charles A. Pneumococcal bacteremia with pneumonia. Chest 1992; 101: 150-155.

80. Jordens J, Paul J, Bates J, Beaumont C, Kimari J, Gilks C. Characterization of Streptococcus pneumoniae from human immunodeficiency virus-seropositive patients with acute and recurrent pneumonia. J Infect Dis 1995; 172: 983-987.

81. Sheikh S, Madiraju K, Steiner P, Rao M. Bronchiectasis in pediatric AIDS. Chest 1997; 112: 1202 1207.

82. Osmond $\mathrm{D}$, Chin $\mathrm{D}$, Glassroth $\mathrm{J}$, et al. Impact of bacterial pneumonia and Pneumocystis carinii pneumonia on human immunodeficiency virus disease progression. Clin Infect Dis 1999; 29: 536-543.

83. Kaplan J, Janoff E, Masur H. Do bacterial pneumonia and Pneumocystis carinii pneumonia accelerate progression of human immunodeficiency virus disease? Clin Infect Dis 1999; 29: 544-546.

84. Moriuchi M, Moriuchi H, Turner W, Fauci A. Exposure to bacterial products renders macrophages highly susceptible to T-tropic HIV-1. J Clin Invest 1998; 102: 1540-1550.

85. Moriuchi H, Moriuchi M, Mizell S, Ehler L, Fauci A. In vitro reactivation of human immunodeficiency virus 1 from latently infected, resting CD4+T cells after bacterial stimulation. J Infect Dis 2000; 181: 20412044.

86. Bush C, Donovan R, Markowitz N, Kuale P, Saravolatz L. A study of HIV RNA viral load in 
AIDS patients with bacterial pneumonia. $J$ Acquir Immune Defic Syndr 1996; 13: 23-26.

87. Morris A, Huang L, Bacchetti $\mathrm{P}$, et al. Permanent decline in pulmonary function following pneumonia in human immunodeficiency virus-infected persons. Am J Respir Crit Care Med 2000; 162: 612-616.

88. Agostini C, Trentin L, Zambello R, Semenzato G. HIV-1 and the lung. Am Rev Respir Dis 1993; 147: $1038-1049$.

89. Lane H, Masur H, Edgar L, Whalen G, Rook A, Fauci A. Abnormalities of B-cell activation and immunoregulation in patients with the acquired immunodeficiency syndrome. $N$ Engl J Med 1983; 309: 453-458.

90. Pahwa S, Quilop M, Lange M, Pahwa R, Grieco M. Defective B-lymphocyte function in homosexual men in relation to the acquired immunodeficiency syndrome. Ann Intern Med 1984; 101: 757-763.

91. Lane H, Depper J, Greene W, Whalen G, Waldmann T, Fauci A. Qualitative analysis of immune function in patients with the acquired immunodeficiency syndrome. $N$ Engl J Med 1985; 313: 79-84.

92. Janoff E, O'Brien J, Thompson P, et al. Streptococcus pneumoniae colonization, bacteremia and immune response among persons with human immunodeficiency virus infection. $J$ Infect Dis 1993; 167: 4956.

93. Moir S, Malaspina A, Ogwaro K, et al. HIV-1 induces phenotypic and functional perturbations of B cells in chronically infected individuals. Proc Natl Acad Sci USA 2001; 98: 10362-10367.

94. Fahy R, Diaz P, Hart J, Wewers M. BAL and serum IgG levels in healthy asymptomatic HIV-infected patients. Chest 2001; 119: 196-203.

95. Murphy $\mathrm{P}$, Lane H, Fauci A. Impairment of neutrophil bactericidal capacity in patients with AIDS. J Infect Dis 1988; 158: 627-633.

96. Lipman M, Johnson M, Poulter L. Functionally relevant changes occur in HIV-infected individuals' alveolar macrophages prior to the onset of respiratory disease. AIDS 1997; 11: 765-772.

97. Hundt M, Heiken H, Schmidt R. Association of low mannose-binding lectin serum concentrations and bacterial pneumonia in HIV infection. AIDS 2000; 14: $1853-1874$.

98. Lyon R, Haque A, Asmuth D, Woods G. Changing patterns of infections in patients with AIDS: a study of 279 autopsies of prison inmates and non incarcerated patients in a university hospital in Eastern Texas. 1984-1993. Clin Infect Dis 1996; 23: 241-247.

99. Stein M, O'Sullivan P, Wachtel T, et al. Causes of death in persons with human immunodeficiency virus infection. JAMA 1992; 93: 387-390.

100. Afessa B, Green W, Chiao J, Frederick W. Pulmonary complications of HIV infection: autopsy findings. Chest 1998; 113: 1225-1229.

101. Hoover D, Saah A, Bacellar H, et al. Clinical manifestations of AIDS in the era of Pneumocystis prophylaxis. N Engl J Med 1993; 329: 1922-1926.

102. Pitkin A, Grant A, Foley N, Miller R. Changing patterns of respiratory disease in HIV positive patients in a referral centre in the United Kingdom between 1986-7 and 1990-1. Thorax 1993; 48: 204-207.

103. McNaghten A, Hanson D, Jones J, Dworkin M, Ward $\mathbf{J}$, and the Adult/Adolescent Spectrum of Disease Group. Effects of antiretroviral therapy and opportunistic illness primary chemoprophylaxis on survival after AIDS diagnosis. AIDS 1999; 13: 16871695.

104. Keller D, Breiman R. Preventing bacterial respiratory tract infections among persons infected with human immunodeficiency virus. Clin Infect Dis 1995; 21: Suppl. 1, S77-S83.

105. Cadranel J, Girard P, Mayaud C. Prophylaxis of respiratory tract infection during HIV infection. Eur Respir Mon 1995; 2: 288-331.

106. United States Public Health Service/Infectious Diseases Society of America. Prevention of Opportunistic Infections Working Group. 1999 USPHS/IDSA Guidelines for the prevention of opportunistic infections in persons infected with human immunodeficiency virus. Ann Intern Med 1999; 131: 873-908.

107. Klein R, Selwyn P, Paude D, Pollar D, Freeman K, Schiffman G. Response to pneumococcal vacccine among symptomatic heterosexual partners of persons with AIDS and intravenous drug users infected with HIV. J Infect Dis 1989; 16: 826-831.

108. Kroon F, Vandissel J, De Jong J, Van Furth R. Antibody response to influenza, tetanus and pneumococcal vaccines in $\mathrm{HIV}$-seropositive individuals in relation to the number of CD4+ lymphocytes. AIDS 1994; 8: 469-476.

109. Rodriguez-Barradas M, Musher D, Lahart C, et al. Antibody to capsular polysaccharides of Streptococcus pneumoniae after vaccination of human immunodeficiency virus-infected subjects with 23-valent pneumococcal vaccine. J Infect Dis 1992; 165: 553-556.

110. Rodriguez-Barradas M, Groover J, Lacke C, et al. IgG antibody to pneumococcal capsular polysaccharide in human immunodeficiency virus-infected subjets: persistence of antibody in responders, revaccination in nonresponders, and relationship of immunoglobulin allotype to response. J Infect Dis 1996; 53: 1347-1353.

111. Guerrero M, Kruger S, Sattoh A, et al. Pneumonia in HIV-infected patients: a case-control survey of factors involved in risk and prevention. AIDS 1999; 13: 19711975.

112. Breiman R, Keller D, Phelan M, et al. Evaluation of effectiveness of the 23-valent pneumococcal capsular polysaccharide vaccine for HIV-infected patients. Arch Intern Med 2000; 160: 2633-2638.

113. Dworkin M, Ward J, Hanson D, Jones J, Kaplan J and and the Adult and Adolescent Spectrum of HIV Disease Project. Pneumococcal disease among human immunodeficiency virus-infected persons: incidence, risk factors, and impact of vaccination. Clin Infect Dis 2001; 32: 794-800.

114. French N, Nakiyingi J, Carpenter L, Lugada E, Watera C, Moi K. 23-Valent pneumococcal polysaccharide vaccine in HIV-1 infected Ugandan adults: double-blind randomised and placebo controlled trial. Lancet 2000; 355: 2106-2111.

115. French N, Gilks C, Mujugira A, Fasching C, O'Brien $J$, Janoff E. Pneumococcal vaccination in HIV-1 infected adults in Uganda: humoral response and two vaccine failures. AIDS 1998; 12: 1683-1689.

116. Hardy W, Feinberg J, Finkelstein D, et al. A controlled trial of trimethoprim-sulfamethoxazole or aerosolized pentamidine for secondary prophylaxis of Pneumocystis carinii pneumonia in patients with the acquired immunodeficiency syndrome. $N$ Engl J Med 1992; 327: 1842-1848.

117. Mayer H, Rose D, Cohen S, Gurtman A, Cheung T, Szabo S. The effect of Pneumocystis carinii pneumonia 
prophylaxis regimens on the incidence of bacterial infections in HIV-infected patients. AIDS 1993; 7: 1687-1689.

118. Tumbarello M, Tacconelli E, Cauda K, Ortona L. Secondary Pneumocystis carinii pneumonia prophylaxis with trimethoprim-sulphamethoxazole does not prevent bacterial pneumonia in HIV-infected persons. AIDS 1996; 10: 1603-1604.

119. Buskin S, Newcomer L, Koutsky L, Hooton T, Spach D, Hopkins S. Effect of trimethoprim-sulfamethoxazole as Pneumocystis carinii pneumonia prophylaxis on bacterial illness, Pneumocystis carinii pneumonia and death in persons with AIDS. $J$ Acquir Immune Defic Syndr 1999; 20: 201-206.

120. Currier J, Williams P, Feinberg J, et al. Impact of prophylaxis for Mycobacterium avium complex on bacterial infections in patients with advanced human immunodeficiency virus disease. Clin Infect Dis 2001; 32: 1615-1622.

121. Badri M, Ehrlich R, Wood R, Maartens G. Initiating co-trimoxazole prophylaxis in $\mathrm{HIV}$-infected patients in Africa: an evaluation of the provisional $\mathrm{WHO} /$ UNAIDS recommendations. AIDS 2001; 15: 1143 1148.

122. Anglaret X, Chene G, Attia A, et al. Early chemoprophylaxis with trimethoprim-sulphamethoxazole for HIV-1 infected adults in Abidjan, Côte d'Ivoire: a randomised trial. Lancet 1999; 353: 1463-1468.

123. Wiktor S, Sassan-Morokro M, Grant A, et al. Efficacy of trimethoprim-sulfamethoxazole prophylaxis to decrease morbidity and mortality in HIV-1 infected patients with tuberculosis in Abidjan, Côte d'Ivoire: a randomised controlled trial. Lancet 1999; 353: 1469 1475.

124. Martin J, Rose D, Hadley W, Pedreau-Remington F, Lam P, Gerberding J. Emergence of trimethoprimsulfamethoxazole resistance in the AIDS era. $J$ Infect Dis 1999; 18: 1809-1818.

125. Sepkowitz K. Effect of prophylaxis on the clinical manifestations of AIDS-related opportunistic infections. Clin Infect Dis 1998; 26: 806-810.

126. Dworkin M, Williamson J, Jones J, Kaplan J and the Adult and Adolescent Spectrum of HIV Disease Project. Prophylaxis with trimethoprim-sulfamethoxazole for human immunodeficiency virus-infected patients: impact on risk for infectious diseases. Clin Infect Dis 2001; 33: 393-398.

127. Currier J, Williams P, Koletar S, et al. Discontinuation of Mycobacterium avium complex prophylaxis in patients with antiretroviral therapy-induced increases in $\mathrm{CD}^{+}$cell count. Ann Intern Med 2000; 133: 493503.

128. Bernado de Quiros J, Miro J, Pena J, et al. A randomized trial of the discontinuation of primary and secondary prophylaxis against Pneumocystis carinii pneumonia after highly active antiretroviral therapy in patients with HIV infection. $N$ Engl J Med 2001; 344: 159-167.

129. Soriano V, Dona C, Rodriguez-Rosado R, Barreiro P, Gonzalez-Lahoz J. Discontinuation of secondary prophylaxis for opportunistic infections in HIVinfected patients receiving highly active antiretroviral therapy. AIDS 2000; 14: 383-386.

130. Brodt H, Kamps B, Gute P, Knupp B, Staszewski S, Helm E. Changing incidence of AIDS-defining illnesses in the era of antiretroviral combination therapy. AIDS 1997; 11: 1731-1738.

131. Tumbarello M, Tacconelli E, Donati K, Cauda R. HIV-associated bacterial pneumonia in the era of highly active antiretroviral therapy. J Acquir Immune defic Synd 1999; 20: 208-209.

132. Paul S, Gilbert H, Ziecheck W, Jacobs J, Sepkowitz K. The impact of patient antiretroviral therapy in the characteristics of hospitalized patients with HIV infection. AIDS 1999; 13: 415-418.

133. Masliah E, de Teresa R, Mallory M, Hansen L. Changes in the pathological findings at autopsy in AIDS cases for the last 15 years. AIDS 2000; 14: 6974.

134. Lederberger B, Egger M, Erard V, et al. AIDS-related opportunistic illnesses occuring after initiation of potent antiretroviral therapy. JAMA 1999; 282: $2220-2226$.

135. Narita M, Ashkin D, Hollender E, Pitchenik A. Paradoxical worsening of tuberculosis following antiretroviral therapy in patients with AIDS. Am J Respir Crit Care Med 1998; 158: 157-161.

136. Wislez M, Bergot E, Antoine M, et al. Acute respiratory failure following HAART introduction in patients treated for Pneumocystis carinii pneumonia. Am J Respir Crit Care Med 2001; 164: 847-851.

137. Lundberg B, Davidson A, Burman W. Epidemiology of Pneumocystis carinii pneumonia in an era of effective prophylaxis: the relative contribution of non-adherence and drug failure. AIDS 2000; 14: 2559-2566.

138. Laurichesse H, Mortimer J, Evans B, Farrington P. Pre-AIDS mortality in HIV-infected individuals in England, Wales and Northern Ireland, 1982-1996. AIDS 1998; 12: 651-658. 